\title{
PERCEPÇÕES SOBRE MEIO AMBIENTE EM UMA ESCOLA NO MUNICÍPIO DE ARACAJU/SE
}

\author{
PERCEPTIONS ABOUT THE ENVIRONMENT AT A SCHOOL IN THE CITY OF ARACAJU / \\ $S E$
}

\author{
Aldeci dos Santos \\ Universidade Federal de Sergipe, SE, Brasil. E-mail: aldeci26@hotmail.com
}

DOI: https://doi.org/10.46550/amormundi.v1i2.33

Recebido em: 28.09.2020

Aceito em: 13.11.2020

\begin{abstract}
Resumo: Atualmente, a educação ambiental pode ser compreendida como sinônimo de reflexão e açáo, que se desenvolve a partir de um processo educativo, permanente e contínuo tendo como objetivo, superar a visão meramente ecológica, transpondo o olhar para uma dimensão mais abrangente, com discussóes de questôes políticas, sociais, econômicas, culturais e ambientais (SPIRONELLO et al. 2012). As questóes ambientais vêm sendo consideradas cada vez mais urgente para sociedade devido à falta de conhecimento, fazendo com que haja a necessidade da escola em desenvolver projetos de pesquisa sobre o meio ambiente. Sendo assim, o referido trabalho teve como objetivo analisar as concepçóes sobre meio ambiente dos alunos do $6^{\circ}$ ano de uma Escola Municipal, no município de Aracaju/SE. Foram aplicados 42 questionários com perguntas abertas e fechadas, sendo a análise feita de forma qualitativa e quantitativa. Observou-se que os educandos têm uma visão ampla em relação à questão ambiental. Entretanto, também pode-se concluir que os professores não esclarecem seus alunos sobre a temática ambiental e as consequências que os problemas ambientais podem trazer ao meio ambiente.
\end{abstract}

Palavras-chave: Educação Ambiental; Concepçóes; Escola; Meio Ambiente.

Abstract: Currently, environmental education can be understood as a synonym of reflection and action, which develops from an educational process, permanent and continuous with the objective of overcoming the merely ecological vision, transposing the look to a more comprehensive dimension, with discussions of political, social, economic, cultural and environmental issues (SPIRONELLO et al. 2012). Environmental issues have been considered more and more urgent for society due to the lack of knowledge, making it necessary for the school to develop research projects on the environment. Therefore, this work aimed to analyze the 6th year students' conceptions about the environment of a Municipal School, in the municipality of Aracaju / SE. 42 questionnaires were applied with open and closed questions, the analysis being made in a qualitative and quantitative way. It was observed that the students have a broad view in relation to the environmental issue. However, it can also be concluded that teachers do not clarify their students about the environmental theme and the consequences that environmental problems can bring to the environment.

Keywords: Environmental Education; Conceptions; School; Environment. 


\section{Introduçáo}

tualmente, a educação ambiental pode ser compreendida como sinônimo de reflexão Le ação, que se desenvolve a partir de um processo educativo, permanente e contínuo tendo como objetivo, superar a visão meramente ecológica, transpondo o olhar para uma dimensão mais abrangente, com discussóes de questóes políticas, sociais, econômicas, culturais e ambientais (SPIRONELLO et al. 2012).

Para Guimarães (1995), no trabalho de conscientização dá-se grande importância ao papel ativo do educando na construção de conhecimento, baseado no questionamento dos diferentes valores, em busca de uma formação pessoal que refletirá em novas atitudes. Portanto, a Educação Ambiental não deve se preocupar em transmitir conhecimentos científicos, mas sim, em produzir conhecimentos a partir de experiências direta do dia a dia do aluno. Diante disso, Dias (1994) comenta que a simples transmissão de conhecimentos deve ser evitada.

Além disso, a Educação Ambiental exige uma postura crítica e conhecimento por parte do educador para que este possa desenvolver um ensino mais contextualizado e participativo. Daí surge a necessidade de os educadores terem acesso a cursos que forneçam instrumentos para a prática da Educação Ambiental (OLIVEIRA, 2000).

Essa atualização por parte dos educadores se torna mais urgente porque a Educação Ambiental apresenta uma nova dimensáo a ser incorporada ao processo educacional, trazendo toda uma recente discussão sobre as questôes ambientais e as consequentes transformaçóes de conhecimento, valores e atitudes diante de uma nova realidade a ser construída" (GUIMARÁES, 1995).

De acordo com os Parâmetros Curriculares Nacionais - PCN - (BRASIL, 1997), o conhecimento dos ciclos da natureza e da complexa trama de relaçóes que os possibilitam permite aos alunos compreender a importância da recomposiçáo dos elementos necessários e permanência da vida no planeta. A viabilização desse tipo de ação é de extrema importância, diante da amplitude, rapidez e intensidade das açóes predatórias, que poderá até mesmo inviabilizar a continuidade da vida.

Conforme Leff (2001), o saber ambiental estabelece uma particular relação entre realidade e conhecimento: Não só busca completar o conhecimento da realidade existente, mas orientar a construção de outra organização social que não seria a projeção das tendências atuais para o futuro. É neste sentido que a utopia ambiental abre novas possibilidades, a partir do reconhecimento de potenciais ecológicos e tecnológicos, onde se amalgamam os valores morais, os saberes culturais e o conhecimento científico da natureza na construção de uma nova racionalidade social.

Uma das razóes que tornam a prática de educação ambiental táo complexa para alguns professores, especialmente relacionada a áreas distintas, é o caráter que compóe a educação ambiental e que o permite que o processo pedagógico aconteça sob diferentes aspectos complementares. Assim, é possível a existência de momentos nos quais aconteçam transmissóes de conhecimento, podendo ser até do aluno para o professor, construção do conhecimento, inclusive entre professores de diferentes disciplinas e a desconstruçáo das representaçóes sociais dos alunos e dos próprios professores, fundamentados na interação entre ciências e cotidiano.

Conhecimento científico, popular e representaçôes sociais; participação política e 
intervenção cidadã, deve descartar a relação predominante até entâo de que o professor ensina e o aluno aprende, e estabelecendo o processo dialógico entre geraçôes diferentes, ou seja, professores e alunos, discutindo possibilidades de açóes conjuntas, que possam garantir vida saudável para todos, sempre visando à herança ecológica que será deixada às geraçóes futuras. (CANDIANI, 2004).

\section{Metodologia e área de estudo}

A investigação adotada para a realização deste trabalho baseou-se nos problemas ambientais apresentados no município de Aracaju/SE. A área de estudo escolhida foi uma Escola Municipal da rede pública do referido município.

\section{Aplicaçáo do questionário na escola}

Para a coleta de dados, foram aplicados questionários, pelo fato de ser uma forma de avaliar as concepçóes dos alunos na sua aprendizagem, nos conteúdos que estão sendo ministrados em discussão pelo professor na sala de aula, assim como sobre o meio ambiente. O questionário, segundo Gil (1999, p.128), pode ser definido "como a técnica de investigação composta por um número mais ou menos elevado de questóes apresentadas por escrito às pessoas, tendo por objetivo o conhecimento de opiniôes, crenças, sentimentos, interesses, expectativas, situaçóes vivenciadas etc."

$\mathrm{Na}$ pesquisa participaram 42 alunos do $6^{\circ}$ ano, nos quais responderam a questôes abertas e fechadas concernentes às causas que contribuem para os prejuízos ao meio ambiente, os tipos de problemas ambientais, de que maneira os docentes trabalham os temas relacionados ao meio ambiente dentre outros.

\section{Resultados e discussóes}

Foram pesquisados 42 alunos da escola Dr. Jessé Andrade Fontes, sendo que 40\% dos alunos são do sexo masculino e $60 \%$ do sexo feminino. Além disso, os alunos apresentaram uma faixa etária que variou de 12 a 16 anos. Quanto ao conhecimento em torno do meio ambiente, houve maior número de alunos com um bom nível de conhecimentos sobre o tema. Outros ficaram indecisos em relação à educação ambiental. Os alunos expressaram que o meio ambiente é um lugar com paisagens naturais, outros que o conhecimento contribui para o meio ambiente protegendo os seres vivos no lugar onde vivemos (Fig.1):

Figura 1: Conhecimento sobre as causas dos problemas ambientais
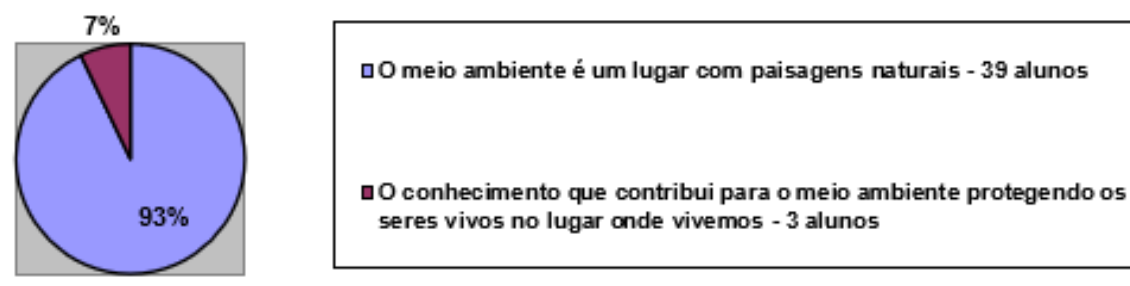

Fonte: Da autora.

A maioria dos alunos, quando questionados a respeito do conhecimento sobre as causas 
dos problemas ambientais que contribui para destruição do meio ambiente, os mesmos definiram que as causas de tais problemas se relacionam a destruição da natureza que vem ocorrendo diariamente pelo homem no seu ecossistema.

O trabalho educacional é componente essencial dessas medidas, as quais são necessárias e de caráter emergencial, pois sabe-se que a maior parte dos desequilíbrios ecológicos está relacionada a condutas humanas inadequadas impulsionadas por apelos consumistas - frutos da sociedade capitalista - que geram desperdício, e ao uso descontrolado dos bens da natureza, a saber, os solos, as águas e as florestas. Os homens são responsáveis diretos pelo que acontece a sua volta e, a menor que haja uma significativa mudança nos valores e nos hábitos de todos os seres humanos, não haverá saída para o planeta (CARVALHO, 2006, p 2).

A maioria (92\%) dos alunos já ouviu falar sobre meio ambiente. Ao serem questionados onde receberam tais informaçóes, a escola, obteve o maior número de resultados em relação a fonte de informação com $64 \%$ das respostas.

Ao serem indagados sobre o que entendiam por meio ambiente $71 \%$ das respostas expressaram que o meio ambiente é o lugar onde vive a maior diversidade existente na natureza, $24 \%$ desses alunos responderam que o meio ambiente é o lugar onde vivem os seres vivos; $5 \%$ não responderam (Fig.2).



Figura 2: Concepção de Ambiente

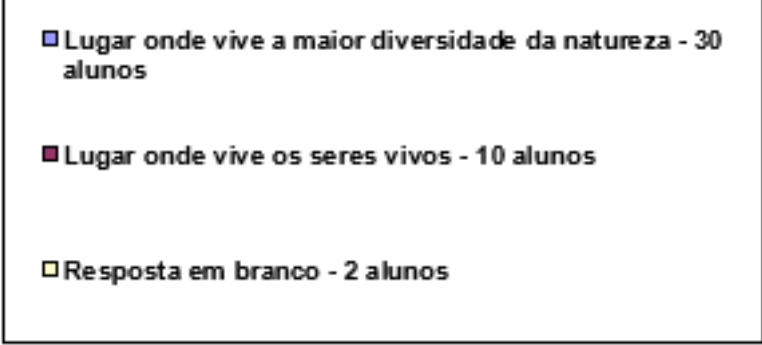

Fonte: Da autora.

Guimarães (1995), ressalta que não existe a separação entre o meio ambiente e o homem. Assim, em Educação Ambiental é preciso que o educador trabalhe a integração ser humano e o meio ambiente e se conscientize de que o ser humano é natureza e não apenas parte dela. Vale ressaltar que a concepçáo do professor sobre o meio ambiente exerce uma influência significativa na construção do conceito de meio ambiente para os alunos.

No questionário, as respostas dos alunos no que se refere à existência dos problemas ambientais na comunidade, evidenciam que eles existem, pois $100 \%$ dos discentes afirmam a existência de problemas ambientais. Desses entrevistados que afirmaram a existência de problemas no questionário, $100 \%$ citaram o lixo como um dos problemas mais graves da sua escola. Segundo Santos (2000), o lixo tem uma significação ideológica, pois cada indivíduo estabelece um critério para o que se deve jogar fora, o que se separa, se exclui e o que não presta. Portanto o lixo é uma questão local, pois cada cidade tem seu lixo com uma composição diferente. A questão dos resíduos e também cultural e, portanto, varia de acordo com cada forma de pensar e agir de cada comunidade. As soluçóes possíveis para os problemas ocasionados pelo lixo só virão a partir desse entendimento (OLIVEIRA, 1992). De acordo com o autor, ninguém joga fora o lixo somente como uma transferência de lugar longe dos olhos de alguém, embora 
perto do "nariz" de alguém e certamente na natureza.

$74 \%$ das respostas dos alunos expressaram que os professores trabalham os temas ambientais com aulas teóricas, $19 \%$ expressaram que o professor trabalha com projetos, $2 \%$ expressou com excursóes, 5\% expressaram com Feira de Ciências (Fig.3).



Nesse sentido, Araújo (1997) ressalta que a escola é o elemento fundamental para a construção da cidadania, ou seja, deve voltar-se para os valores e os problemas da comunidade, e a partir desses valores, construir uma consciência crítica sobre a própria situação local.

Nos questionários, 95\% dos alunos expressaram que na escola náo trabalhava com projetos relacionados ao meio ambiente, $5 \%$ expressaram que a escola trabalhava com projetos (fig. 4).

Figura 4: Existência de projetos sobre Meio Ambiente

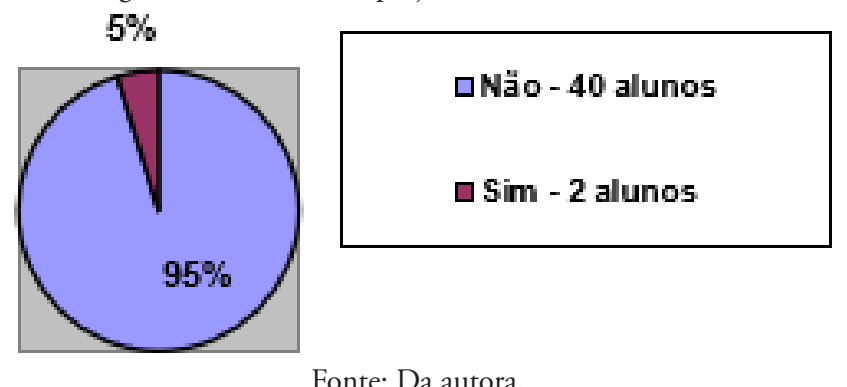

Fonte: Da autora.

É fundamental desenvolver atividades de Educação Ambiental nas escolas, pois essa desempenha um papel importante na hora de educar a comunidade para a recuperação e o gerenciamento ambiental do local (SECRETARIA DO MEIO AMBIENTE, 2003).

Segundo Oliveira (2000), as propostas de ações/atividades, em Educação Ambiental, são concebidas em três áreas de incidência: 1) Educação Formal: projetos voltados para a inserção das questóes ambientais nos currículos escolares de $1^{\circ}$ e $2^{\circ}$ Graus; 2) Educação Não Formal: projetos voltados para trabalho com instituiçốes envolvendo a sociedade; 3) Capacitação: Aperfeiçoamento de pessoal técnico para exercício com atividade de civil, em comunidade, controle, preservação, fiscalização e educação para o meio ambiente, como suporte as açôes de educação formal e não formal.

Dos alunos questionados, $64 \%$ expressaram que a forma de interferência da humanidade no meio ambiente é feita através da destruição da natureza pela humanidade, 36\% expressaram que a humanidade preservar seu meio ambiente (fig. 5). 
Figura 5: Interferências do Homem no Meio Ambiente

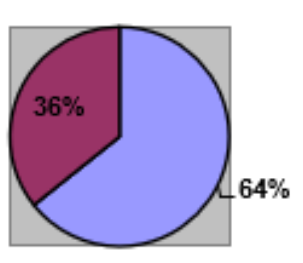

口Destruição da natureza pela humanidade - 27 alunos

$\square$ A humanidade preserva seu meio ambiente - 15 alunos

Fonte: Da autora.

A interferência da humanidade no meio ambiente e a falta de conscientização coloca o planeta em perigo, desta forma, é necessário que haja um trabalho educacional, que faz parte do componente de medidas necessárias e de caráter emergencial, pois sabe-se que a maior parte dos desequilíbrios ecológicos está relacionada a condutas humanas inadequadas, impulsionadas por apelos comunistas - frutos da sociedade capitalista - que geram desperdício, além do uso descontrolado dos bens da natureza, a saber, os solos, as águas e as florestas. Os homens são responsáveis diretos pelo que acontece a sua volta e, a menos que haja uma significativa mudança nos valores e nos hábitos de todos os seres humanos, não haverá saída para o planeta.

Diante desse cenário,

além da formulação de propostas teóricas, da aprovação de leis e da introdução de novas diretrizes curriculares, e orientaçôes didáticas nos sistemas educacionais, além da produção e distribuição de material pedagógico, e necessário que haja mais acompanhamento e maior apoio ao que acontece dentro das escolas, no espaço das salas de aula. É lá que a educação realmente acontece e, quer sejam grandes ou pequenas açóes, elas são extremamente necessárias (CARVALHO, 2006, p. 2).

Já, 48\% expressaram que é possível resolver os problemas ambientais, através da preservação do meio ambiente, $26 \%$ expressaram não desmatar a natureza, $14 \%$ não poluir o meio ambiente, $12 \%$ não opinaram sobre os problemas ambientais (fig. 6).

Figura 6: Soluçáo para os problemas ambientais
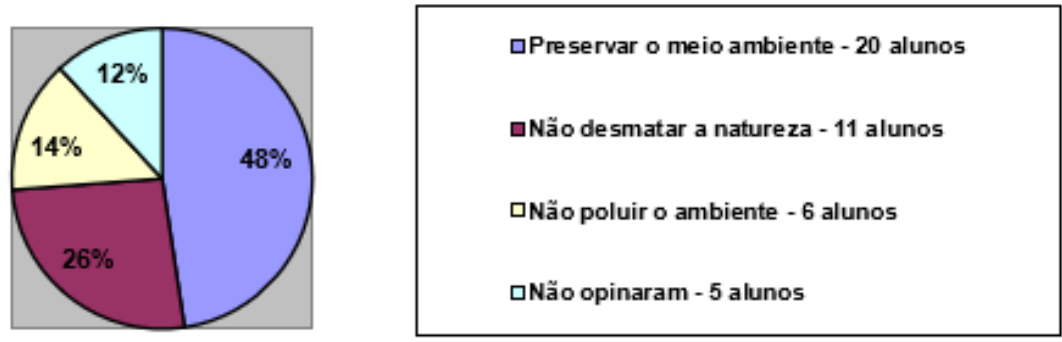

Fonte: Da autora.

Segundo Leff (2001), a problemática ambiental do desenvolvimento deu lugar a um movimento, na teoria e na prática, para compreender suas causas e resolver seus efeitos na qualidade de vida e nas condiçóes de existência da sociedade. O custo social da destruição ecológica e da degradação ambiental gerada pela maximizaçáo do lucro e dos excedentes econômicos a curto prazo deram impulso à emergência de novos atores sociais mobilizados por valores, direitos e demandas que orientam a construçáo de uma racionalidade ambiental.

Quando perguntados o que deveria ser feito para melhor com os problemas ambientais, $24 \%$ alunos não opinaram, 59\% expressou que a conscientização das pessoas para com os problemas ambientais já está ocorrendo na natureza, 10\% expressaram conscientizar as pessoas 
a não poluir o meio ambiente, $7 \%$ não jogar lixo na natureza (fig. 7) .

Figura 7: Ações para melhoria do Ambiente
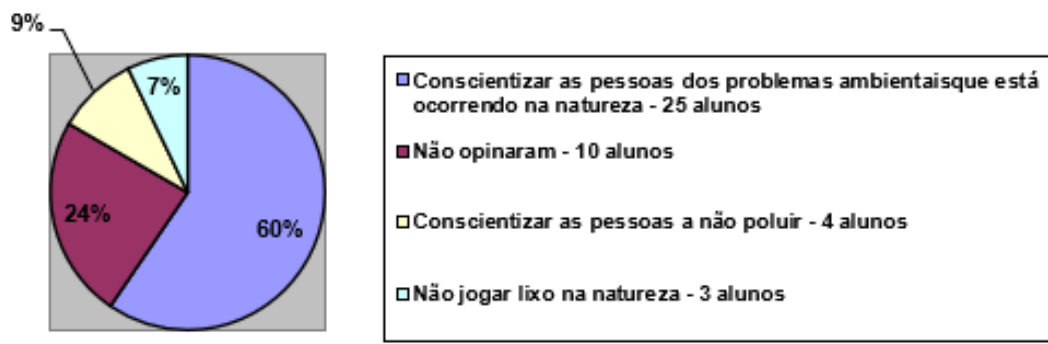

Fonte: Da autora.

Segundo Ruy (2004) tais princípios devem incluir ações visando educar as comunidades procurando sensibilizá-las para as questóes ambientais e mobilizá-las para a modificação de atitudes nocivas e a apropriação de posturas benéficas ao equilíbrio ambiental.

CANDIANI (2004), por sua vez, afirma que a educação ambiental objetiva proporcionar aos indivíduos a compreensão da natureza complexa do meio ambiente, ou seja, levar todos à percepção das interaçóes entre aspectos físicos, socioculturais e político-econômicos que compõem a relação homem/meio. Para esse autor, a educação ambiental busca ainda fornecer maneiras de interpretar a interdependência desses diversos elementos no espaço, levando à utilização mais prudente dos recursos naturais.

Pela prática da educação ambiental pretende-se transformar a concepção da natureza como um elemento exterior ao homem, fazendo com que o mesmo se torne mais responsável, comprometido com os valores éticos e de solidariedade entre os seres vivos e exercite plenamente a cidadania.

Quando questionados sobre os seus atos para preservar o ambiente, 48\% dos alunos opinaram que a conscientização é de cada indivíduo, 19\% opinaram a respeito das poluições, $7 \%$ outros afirmaram que o ambiente é o nosso lugar de sobrevivência, 26\% não opinaram (fig. $8)$.

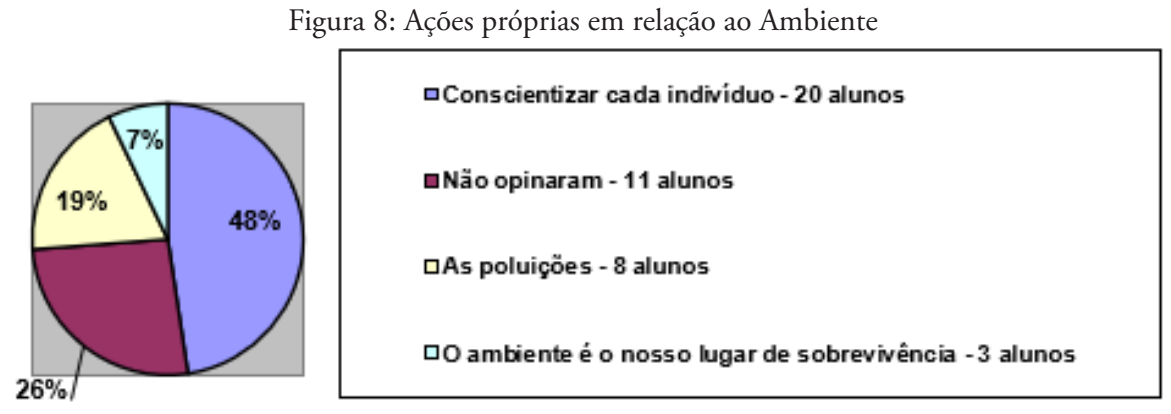

Fonte: Da autora.

Segundo Branco (1998), o grande problema da civilização moderna, industrial e tecnológica é a de não perceber que o homem depende da natureza. À medida que o homem foi desenvolvendo novas tecnologias e ampliando seu domínio sobre os elementos da natureza em geral, os impactos ambientais foram se ampliando em intensidade e extensão. 


\section{Consideraçóes finais}

Através da análise de compreensão sobre as concepções dos alunos do $6^{\circ}$ ano sobre o meio ambiente, observou-se que a maior parte dos alunos conceitua o meio ambiente como lugar onde vivem os seres vivos, com belas de paisagens naturais, relacionando o meio ambiente diretamente com a natureza. Apenas a minoria ver o homem, a casa e a escola como parte integrante do meio ambiente.

Todos os alunos afirmaram a existência dos problemas ambientais em seu povoado, apontado a poluição por lixo como problema mais graves em sua região como uma das situaçóes mais comuns e como um dos principais causadores dos problemas ambientais na escola. Percebeuse, ainda, que houve um aumento expressivo nessa escola em relaçáo a pesquisa realizada nesta escola no que se refere à Educação Ambiental.

A grande parte dos alunos já ouviu falar sobre meio ambiente e educação ambiental, entretanto, poucos sabem como fazê-la. A escola obteve a maior expressão (92\%) desses alunos nas informaçôes citadas e em segundo lugar a televisão que tem o meio de informaçóes ou de comunicação para toda sociedade.

A escola exerce um papel fundamental na hora de educar os alunos e a comunidade em geral sobre os problemas ambientais da região desses alunos. A escola tem grande necessidade de trabalho com projetos relacionados a Educação Ambiental e de outros projetos a serem trabalhados nesse povoado para conscientizar os alunos a diminuir desequilíbrio que está acontecendo no meio ambiente.

\section{Referências}

ARAÚJO, S. C.S. A Educação Ambiental e o contexto educacional brasileiro. Dissertação (Mestrado de Desenvolvimento e Meio Ambiente). Núcleo de Pós-graduação e Estudos do Semiárido, Programa Regional de Pós-graduação em Desenvolvimento e Meio Ambiente PRODEMA, Universidade Federal de Sergipe. Documento Sergipano. Aracaju: UFS, 1997.

BRANCO, S. M. O Meio ambiente em debate. São Paulo: Moderna, 1998.

BRASIL, Secretaria de Educação Fundamental. Parâmetros Curriculares Nacionais Ciências Naturais. 5a a 8a série. Brasília: MEC/SEF, 1997.

CANDIANI, G. Educação Ambiental: percepção e prática sobre Meio ambiente de estudante do ensino fundamental e médio. Revista Eletrônica Mestrado Educação Ambiental, vol.14, janeiro a junho de 2004.

CARVALHO, M. B. S.S. Educaçáo Ambiental: A experiência da Escola Municipal Agrícola. Faculdade de Filosofia, Ciências e Letras de São José do Rio Pardo, disponível em www. centrorefeducacional.com.br. Acesso em 18/07/16.

DIAS, G. F. Educaçáo ambiental: princípios e prática. 3 ed. São Paulo; Gaia, 1994.

GIL, Antônio Carlos. Métodos e técnicas de pesquisa social. 5. ed. São Paulo: Atlas, 1999.

GUIMARĀES, M. A dimensão ambiental na educação. Campinas, SP: Papirus, 1995. 
LEFF, E. Saber ambiental: Sustentabilidade, racionalidade, complexidade poder; tradução de Lúcia Mathilde Endlich Orth-Petrópolis, RJ: Vozes, 2001.

OLIVEIRA, A. S.D. Lixóes: o preço da ignorância. Rio Grandes, RS: Editora Fundação Universidade do Rio Grande, 1992.

OLIVEIRA, E. M. Educaçáo Ambiental uma possível abordagem. Brasília: Ed. IBAMA, 2000 .

RUY, R. A. V. A educaçáa ambiental na escola. Revista Eletrônico de Ciências, vol. 12, Número 26, 2004.

SANTOS, J. Os caminhos do lixo em Campo Grande: disposiçáo de resíduos sólidos na organização do espaço urbano. Campo Grande: UCDB, 2000.

SPIRONELLO, R.L.; TAVARES, F. S.; SILVA, E.P. Educação ambiental: da teoria à prática, em busca da sensibilização e conscientização ambiental. Revista Geonorte, v.3, n.4, p.140-152, 2012. 